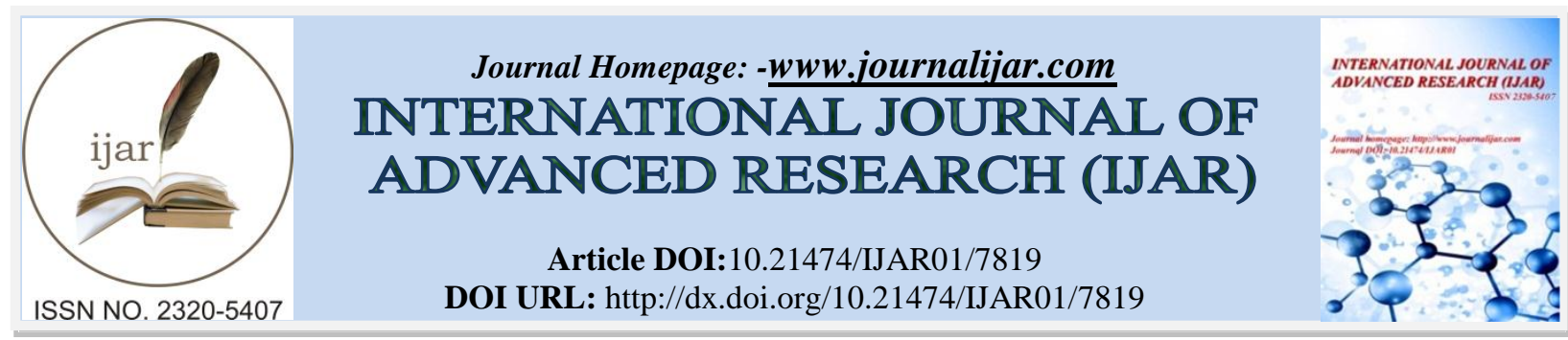

RESEARCH ARTICLE

\title{
PREVALENCE OF SLEEP DISORDERED BREATHING AND EXCESSIVE DAY TIME SLEEPINESS AMONG HEAVY VEHICLE DRIVERS IN TRIVANDRUM, SOUTH INDIAN CITY: A CROSS SECTIONAL STUDY.
}

Sajeesh Parameswaran, Arun C K and Jithu L Prasad.

Ananthapuri Hospitals and Research Institute, Trivandrum, India.

\section{Manuscript Info}

Manuscript History

Received: 6 August 2018

Final Accepted: 8 September 2018

Published: October 2018

Keywords:

Drivers, SDB, RTA, snoring, EDS.

\begin{abstract}
International classification of sleep disorders lists more than 80 types of sleep disorders. Epidemiologic studies from different parts of India have uncovered the high prevalence of undiagnosed sleep disorders, especially sleep disordered breathing (SDB). Undiagnosed SDB is increasingly being recognized as a causative factor associated with excessive daytime sleepiness and lack of concentration leading to poor occupational efficiency and increasing risk of motor vehicle accidents. Currently, there are limited published data on the prevalence of sleep disorders in Indian commercial drivers here the number of road accidents are on the rise. Therefore, we conducted a pilot study to understand the sleep patterns and sleep-related complaints of heavy vehicle drivers in Trivandrum, the capital city of Kerala, Southern most state of India and its relation to road traffic accidents(RTA).In our study, we noted a significant number of drivers with SDB and excessive day time sleepiness. The drivers who met with RTA had a positive correlation with higher BMI, high Epworth Sleepiness score, snoring and SDB.
\end{abstract}

Copy Right, IJAR, 2018,. All rights reserved.

\section{Introduction:-}

International classification of sleep disorders lists more than 80 types of sleep disorders (ICSD classification 2005). Epidemiologic studies from different parts of India have uncovered the high prevalence of undiagnosed sleep disorders, especially sleep disordered breathing (SDB) ranging from 7.5\%-9.3\% in middle aged men (Panda et al. 2012, Suri et al. 2008, Udwadia et al. 2004, Vijayan et al, 2004). A community-based study done among middleaged urban Indians found that male gender, high body-mass index and abdominal obesity were independently associated with SDB (Reddy et al 2009). Undiagnosed SDB is increasingly being recognized as a causative factor associated with excessive daytime sleepiness (EDS) and lack of concentration leading to poor occupational efficiency and increasing risk of motor vehicle accidents (Colten et al. 2006, Findley et al. 1989, Howard et al. 2004). Currently, there are limited published data on the prevalence of sleep disorders in Indian commercial drivers here the number of road accidents are on the rise. Therefore, we conducted a pilot study to understand the sleep patterns and sleep-related complaints of heavy vehicle drivers in Trivandrum, the capital city of Kerala, Southern most state of India and its relation to road traffic accidents (RTA). 


\section{Objective:}

The aim of the study was to assess the sleep patterns, working schedules, incidence of excessive day time sleepiness, RTA and prevalence of SDB among heavy vehicle drivers.

\section{Methods:-}

One hundred and twenty six male heavy vehicle drivers in the Trivandrum city were randomly selected for the study. Interview was done in the afternoon at their rest rooms. A heavy vehicle driver was defined as a person engaged in driving public transport bus or lorry in Trivandrum city. The data can be obtained using a structured sleep questionnaire; encompassing demographic details, height, weight and body mass index (BMI), nature of work, shift versus non-shift worker, sleep pattern, sleep hygiene, drowsy driving, co-existing medical illnesses if any, substance abuse etc. The questionnaire was adapted from the two well internationally validated sleep scales such as Epworth sleepiness scale and Pittsburg sleep quality index (Buysse et al. 1989, Johns et al. 1991, Bhatia et al 2004). The questions related to all common sleep disorders like apneas, periodic leg movements, insomnia, and parasomnia were included. Excessive day time sleepiness (EDS) was quantified using Epworth sleepiness scale (ESS) with a score $\geq 10$, considered as significant for SDB. Loud snoring, excessive day time sleepiness, early morning head ache, choking and dryness of mouth during sleep, multiple arousal and decreased sleep satisfaction were considered as signs of sleep disordered breathing. All subjects were asked whether they had met with any RTA in the last 1 year. The questionnaire was explained to the subjects and assistance was provided to read or further clarify the questions if necessary.

The baseline characteristics of the drivers' sleep patterns were studied in detail. The incidence of sleep disordered breathing, excessive day time sleepiness and sleep patterns were analyzed and the occurrence of drowsy driving and RTA were tabulated. We studied the inter group comparison between the drivers who met with RTA and the drivers who have not met with RTA. Various characteristics of the shift workers and non shift workers were also been analyzed.

The demographic characteristics of the population studied were expressed in mean and percentage. The comparisons between the groups were done by univariateanalysis and Fisher's exact test. All the statistical analysis were done using SPSS version 16.0 software (SPSS Inc,Illinois, Chicago).

\section{Results:-}

A total of 126 respondents (all males) participated in the study. Their mean age was 40 years (range 25-55 years). Their baseline characteristics are depicted in Table 1. Out of 126 drivers; only 9 (7.14\%) reported decreased sleep time; $53(42.06 \%)$ had obesity; 40(31.74\%) had significant excessive day time sleepiness with high ESS score; $28(22.22 \%)$ reported snoring loud enough to disturb others; $88(69.84 \%)$ drivers were doing shift-work; 62(49.20\%) were regularly taking alcohol and 40(31.74\%) were habitual smokers. $14(11.11 \%)$ complained of stress related to their occupational stress and had features of self-reported depression. SDB was identified in 15 drivers (11.9\%). Out of them, 12 drivers reported that their driving had been affected by sleepiness; and 4 drivers reported RTA due to sleepiness while driving.

The drivers were categorized in to two groups further: those who met with RTA and those who have not (Table 2). Those who met with RTA while driving had a higher BMI (>30.1), loud snoring, ESS $>10$, and SDB symptoms as compared to the drivers who never met with RTA while driving, which was statistically significant $(p<0.05)$.

Majority, 88(69.84\%) drivers were doing shift dutiesi.e. both day and night shifts. The intergroup comparison between the day shift and day-night shift workers were done. Higher ESS score and snoring index noted in day-night shift working group ( $p$ value $<0.05$ (Table 3). All the RTA reported in the study occurred in drivers working in daynight shift. Also, the presence of other related factors like depression, smoking and alcohol use failed to achieve statistically significant in bivariate analysis ( $\mathrm{p}>0.05)$. 
Table 1:-Baseline characteristics of 126 heavy vehicle drivers

\begin{tabular}{|l|l|l|l|}
\hline No. & Type & No. of drivers & Percentage (\%) \\
\hline 1 & Total sleep time $<5$ hrs & 9 & 7.14 \\
\hline 2 & BMI $25 \mathrm{~kg} / \mathrm{m}^{2}$ & 53 & 42.06 \\
\hline 3 & Smoking & 40 & 31.74 \\
\hline 4 & Alcohol consumption & 62 & 49.20 \\
\hline 5 & Shift duty & 88 & 69.84 \\
\hline 6 & Snoring & 28 & 22.22 \\
\hline 7 & Depression & 14 & 11.11 \\
\hline 8 & Excessive day time sleepiness & 40 & 31.74 \\
\hline 9 & Follow good sleep hygiene & 62 & 49.20 \\
\hline 10 & Sleep Disordered Breathing & 15 & 11.9 \\
\hline 11 & Dozed of while driving & 12 & 9.5 \\
\hline 12 & Accidents due to falling asleep & 4 & 3.2 \\
\hline
\end{tabular}

Table 2:-Inter group comparison between drivers who met RTA with rest of the group

\begin{tabular}{|l|l|l|l|l|}
\hline Subjects & BMI $>$ 25 & Snoring & ESS $>$ 10 & SDB \\
\hline Drivers with RTA(N=4) & 4 & 4 & 4 & 4 \\
\hline $\begin{array}{l}\text { Rest of the group } \\
(\mathrm{N}=122)\end{array}$ & 50 & 52 & 28 & 11 \\
\hline$p^{*}$ & 0.032 & 0.036 & 0.003 & $<0.0001$ \\
\hline
\end{tabular}

BMI- body mass index, ESS- Epwoth sleepiness score, RTA-road traffic accident, N-number, SDB-Sleep Disordered Breathing $\quad * p$ value calculated by Fisher's exact test

Table 3:-Comparisons of various parameters among the day shift workers and day-night shift workers

\begin{tabular}{|l|l|c|l|l|l|}
\hline Groups & Total number & ESS>10 & Snoring & RTA & $\begin{array}{l}\text { Slept-off while } \\
\text { driving }\end{array}$ \\
\hline $\begin{array}{l}\text { Day shift } \\
\text { Workers }\end{array}$ & 38 & $4(10.53 \%)$ & $6(15.79 \%)$ & $0(0 \%)$ & $2(5.3 \%)$ \\
\hline $\begin{array}{l}\text { Day-night shift } \\
\text { workers }\end{array}$ & 88 & $28(31.82 \%)$ & $50(56.82 \%)$ & $4(4.5 \%)$ & $10(11.36 \%)$ \\
\hline$p$ value & & 0.013 & 0.0001 & 0.314 & 0.337 \\
\hline
\end{tabular}

ESS-Epworth sleepiness score, RTA-road traffic accident ; $p$ value calculated by Fisher's exact test

\section{Discussion:-}

According to Road accident information system (RAIS) data published by Kerala State Crime record Bureau, for the year 2010, a total of 35,046 RTAs were reported. Trivandrum city with a population of 7,50,000 experienced 1,646 RTAs in the same period, responsible for 18.66 deaths per 100,000 population (Criminal intelligence Gazette January 2011). RAIS data suggests that around $9 \%$ of RTA are due to heavy motor vehicles, most of which lead to grievous injuries or death. Given the understanding of the prevalence of RTA made by heavy motor vehicle drivers, we undertook a pilot study on heavy motor vehicle drivers to assess for prevalence of sleep disordered breathing and incidence of excessive day time sleepiness in them which might contribute to such high RTA.

The present study revealed that nearly $60 \%$ of drivers reported at least one sleep-related complaint. This is comparable to other published data where prevalence of sleep complaints in commercial drivers ranged from 60$75 \%$ (Hui DSC 2007,). Prevalence of SDB of the present sample of drivers was around $12 \%$ and $9 \%$ of drivers candidly admitted having dozed off while on duty. This was much lower than the questionnaire study from Thailand, where they reported $28.7 \%$ of drivers having fallen asleep behind the wheel (Leechawengwongs 2006). Even though; this is really significant in public transport driver population.

Excessive sleepiness has been found to have a strong association with sleep deprivation, day-night shift work, higher BMI and snoring (Mello M D et al. 2000). In the present study; around $70 \%$ of the drivers were doing day-night shift work, $42 \%$ were obese and $22 \%$ were snorers. We found a strong association between theses parameters with excessive day time sleepiness. 
Sleepiness related to inadequate quantity and quality of sleep is widely recognized as a risk factor of RTA among drivers (Hartenbaum $\mathrm{N}$ et al 2006). In our study; around 50\% does not give any importance for sleep and follows good sleep hygiene. Around $7 \%$ drivers get lesser time for sleep ( $<5$ hours in the night). Many of the drivers had poor sleep hygiene and even get lesser time for sleep.

Obstructive sleep apnea increases accident risk by 2 to 7 fold (Robb G et al 2008). Present pilot study revelaed $11.9 \%$ had strong symptoms of Sleep apnea syndrome. Population based studies have identified male gender, middle age, high BMI, severity of OSA, oxygen saturation and EDS (Bearpark H et al 1995, Tregear S et al 2009) as risk factors to high accident rates among commercial motor vehicle drivers. Our study we found that the subjects with higher ESS, BMI> 25, snoring and history of apnea had a statistically significant association with RTA.

Another factor affecting driving is alcohol consumption, which was reported by $49.2 \%$ of our sample. Alcohol is known to modify sleep in a significant manner, producing both subjective alterations evaluated with scales and questionnaires and objective alterations observed in polysomnography. Consumption of alcohol is well known to alter the driving skills and vigilance too (Banks S et al 2004).

Overall, awareness of sleep problems in the drivers and its impact on driving is low among health care professionals and policy makers. We believe that our study is a positive step towards sensitizing medical profession and policy makers regarding the importance of screening for and early recognition of sleep disorders in the commercial driving population, thereby improving road safety. Reliability of various low cost methods of screening for sleep apnea syndromes were studied by different centers .(Gurubhagavatula I et al 2004). It can be implemented in commercial drivers to avoid drowsy driving and RTA. Diagnosing sleep apnea syndrome and giving appropriate treatment will significantly reduce road traffic accident rate (Horstmann S et al 2000). Majority of the drivers work in day and night; better sleep hygiene, life style modification and work schedule will help to reduce RTA. A moderate reduction in weight can also change apnenichypoapneic index; scale used to assess the degree of SDB (Peppard P E et al 2000).

Our study, first of its kind from South India is not without its limitations. Even though we found high rates of EDS and snoring in our study population; detailed polysomnography was not performed to confirm the diagnosis of sleep apnea syndrome. A recent study from Australia has suggested that self reporting of sleep complaints and EDS may underestimate prevalence of SDB in at risk populations (Sharwood L et al 2012). They found that even though only $12 \%$ reported EDS, home PSG monitoring uncovered probable OSA in $41 \%$ of the screened drivers. We are now proceeding with home PSG of the same study population as the second phase, which will shed more concrete evidence into this less recognized public health problem.

\section{Conclusion:-}

In our study, we noted a significant number of drivers with SDB and excessive day time sleepiness. The drivers who met with RTA had a positive correlation with higher BMI, high Epworth Sleepiness score, snoring and SDB.

No conflict of interest

\section{References:-}

1. Banks S, Catcheside P, Lack L, Grunstein RR, McEvoy RD. Low levels of alcohol impair driving simulator performance and reduce perception of crash in partially sleep deprived subjects. Sleep. 2004;27:1063-1067.

2. Bearpark H, Elliott L, Grunstein R, Schneider H, Althaus W, Sullivan C. Snoring and sleep apnea: A population study in Australian men. Am J RespirCrit Care Med. 1995;151:1459-65.

3. Bhatia M, Prasad K, Pandey RM. Inter-observer and intra-observer reliability of a sleep questionnaire in Indian population. J Assoc Physicians India. 2004;52:464-6

4. Buysse D J, Reynolds C F 3rd, Monk T H, Berman S R, Kupfer D J. The Pittsburgh Sleep Quality Index: a new instrument for psychiatric practice and research. Psychiatry Res. 1989;28:193-213

5. Colten H R, Altevogt B M. Sleep disorders and sleep deprivation: An unmet public health problem. Washington DC: National Academies Press. 2006; 67-209. 
6. Criminal intelligence Gazette January 2011, Road accident information system State Crime Records Bureau (SCRB), Trivandrum, Kerala, India

7. Feige, B., Gann, H., Brueck, R., Hornyak, M., Litsch, S., Hohagen, F., \& Riemann, D. Effects of alcohol on polysomnographically recorded sleep in healthy subjects. Alcoholism: Clinical and Experimental Research, 2006:30(9), 1527-1537.

8. Findley L, Smith C, Hooper J, Dineen M, Suratt PM. Treatment with nasal CPAP decreases automobile accidents in patients with sleep apnea. Am J RespirCrit Care Med. 2000;161:857-9.

9. Gurubhagavatula I, Maislin G, Nkwuo JE, Pack AI. Occupational screening for obstructive sleep apnea in commercial drivers. Am J RespirCrit Care Med. 2004;170:371-376.

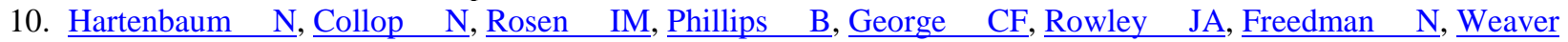

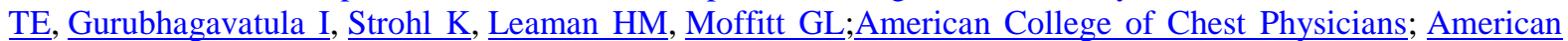
College of Occupational and Environmental Medicine; National Sleep Foundation.Sleep apnea and commercial motor vehicle operators: Statement from the joint task force of the American College of Chest Physicians, the American College of Occupational and Environmental Medicine, and the National Sleep Foundation. Chest. 2006;130:902-5.

11. Horstmann S, $\underline{\text { Hess CW}}$, Bassetti C, Gugger M, Mathis J. Sleepiness-related accidents in sleep apnea patients. Sleep. 2000;23:383-389.

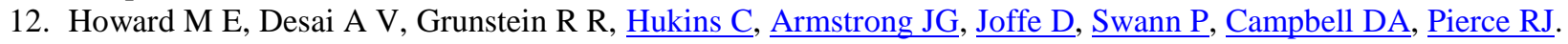
Sleepiness, sleep-disordered breathing, and accident risk factors in commercial vehicle drivers. Am J RespirCrit Care Med. 2004;170:1014-1021.

13. Hui DSC. Evaluation of subjective sleepiness and prevalence of obstructive sleep apnoea and sleep-disordered breathing in a population of commercial driversHong Kong Med J. 2007;13:S36-9

14. ICSD- The international classification of sleep disorders: Diagnostic and coding manual; 2 nd ed. Westchester, Illinois: American Academy of Sleep Medicine; 2005.

15. Johns M W. A new method for measuring daytime sleepiness: the Epworthsleepinessscale. Sleep. 1991 Dec;14(6):540-5

16. LeechawengwongsM ,Leechawengwongs E, Sukying C ,Udomsubpayakul U. Role of drowsy driving in traffic accidents: A questionnaire survey of Thai commercial bus/truck drivers- J Med Assoc Thai. 2006; 89:1845-50.

17. Mello M D, Santana MG, Souza LM, Oliveira PC, Ventura ML, Stampi C, Tufik S. Sleep patterns and sleeprelated complaints of Brazilian interstate bus drivers. Braz J Med Biol Res. 2000;33:71-7.

18. National Sample Survey 2011-12, Ministry of Statistics and Programme Implementation, Government of India

19. Panda S, Taly AB, Sinha S, Gururaj G, Girish N, Nagaraja D. Sleep-related disorders among a healthy population in South India. Neurol India. 2012;60:68-74.

20. Peppard P E, Young T, Palta M, Dempsey J, Skatrud J. Longitudinal study of moderate weight change and sleep-disordered breathing. Jama. 2000;284:3015-21.

21. Reddy E V, Kadhiravan T, Mishra HK, Sreenivas V, Handa KK, Sinha S, Sharma SK. Prevalence and risk factors of obstructive sleep apnea among middle-aged urban Indians: A community-based study. Sleep Med. 2009; 10:913-8.

22. Robb G, Sultana S, Ameratunga S, Jackson R. A systematic review ofepidemiological studies investigating risk factors for work-related road traffic crashes and injuries. Inj Prev. 2008;14:51-8.

23. Roehrs T, Yoon J, Roth T. Nocturnal and next-day effects of ethanol and basal level of sleepiness. Human Psychopharmacology 1991: 6:307-311.

24. Sharwood LN, Elkington J, Stevenson M, Grunstein RR, Meuleners L, Ivers RQ, Haworth N, Norton R, Wong KK. Assessing sleepiness and sleep disorders in Australian long-distance commercial vehicle drivers: selfreport versus an "at home" monitoring device. Sleep. 2012;35:469-75.

25. StuttsJ ,Wilkins JW, OsbergS,Vaughn BV. Driver risk factors for sleep-related crashes.Accid Ana Prev. 2003;35: 321-331.

26. Suri JC, Sen MK, Adhikari T. Epidemiology of sleep disorders in the adult population of Delhi-a questionnaire based study. Indian J Sleep Med. 2008; 3:128-37.

27. Tregear S; Reston J; Schoelles K; Phillips B. Obstructive sleep apnea and risk of motor vehicle crash: systematic review and meta-analysis. J Clin Sleep Med. 2009;5:573-581.

28. Udwadia ZF, Doshi AV, Lonkar SG, Singh CI. Prevalence of sleep-disordered breathing and sleep apnea in middle-aged urban Indian men. Am J RespirCrit Care Med. 2004;169:168-73.

29. Vijayan V K, Patial K. Prevalence of obstructive sleep apnoea syndrome in Delhi, India. Chest. 2006: 130: 92S

30. Zhang L, Samet J, Caffo B, Punjabi, N. M. Cigarette smoking and nocturnal sleep architecture. American Journal of Epidemiology.2006: 164(6), 529-537. 